\title{
Nuevas piezas de arqueología cristiana altomedieval en Asturias
}

\author{
César García de Castro Valdés *
}

Desde la publicación de Arqueología cristiana de la Alta Edad Media en Asturias (Oviedo, Real Instituto de Estudios Asturianos, 1995) he tenido conocimiento de la existencia de la siguiente relación de piezas adscribibles al mismo periodo y temática:

I. Epigrafía: epitafio de Santa María de Bullaso (Eilao).

2. Equipamiento litúrgico: ara de altar de la capilla de Santa Susana y San Daniel de la Casa de la Torre de San Martín del Valledor (Allande); tenante de altar, pila bautismal y pila de agua bendita de la parroquial de Santa María de Bullaso (Eilao).

\section{Elementos arquitectónicos de iluminación:} ventanas exentas de la capilla de Santo Tomás de Priandi (Nava) y la parroquial de San Bartolomé de Puelles (Villaviciosa).

De estas piezas he dedicado un trabajo monográfico a la ventana de Puelles (GARCÍA DE CASTRO VALDÉS, 1996: 28I-284), por lo que no será objeto de estudio en esta entrega. Las restantes disponen de escuetas menciones en obras generales de reciente aparición, o se encuentran inéditas.

\section{Epitafio de Santa María de Bullaso (Eilao) (lám. I; fig. I).}

Ha sido escuetamente mencionada en dos obras de carácter general sobre la región (GRAN
ATLAS DEL PRINCIPADO DE ASTURIAS, 1996: I59; LÓPEZ ROCA, 1997: 153). En ambas se limita la cita a reseñar la existencia, postulando una cronología entre los siglos VII y X.

Se encuentra empotrado en el muro $S$ del pórtico occidental del templo parroquial, por lo que sólo es posible examinar el anverso. Por lo mismo, las dimensiones reales no pueden ser conocidas, apuntándose las de la superficie visible. No obstante, el cuidado con el que ha sido empotrada permite suponer que las dimensiones reales han sido respetadas.

Se trata de una estela discoidal funeraria, labrada en esquisto, de contorno semicircular sobre vástago triangular invertido. La inscripción se dispone a lo largo de una corona circular que rodea un círculo central, delimitado por dos circunferencias concéntricas incisas. En el interior de este círculo se ha labrado una cruz latina incisa, con los brazos rematados por trazos incisos perpendiculares, sobrepuesta a un pequeño taladro situado en el centro geométrico de la circunferencia. La altura máxima apreciada es de 49'5 cm. La anchura es de 34 $\mathrm{cm}$. El diámetro exterior del círculo es de 22 , el interior de $18^{\prime} 5 \mathrm{~cm}$.

La inscripción se desarrolla hacia la derecha, a partir de una cruz incisa situada en el ápice de la corona circular. Ocupa 3/4 del desarrollo de la misma. El cuarto superior izquierdo presenta incisiones indescifrables, de menor entidad que las de la leyenda, por lo que es

* Arqueólogo. 
dudoso que pertenezcan a ésta. La lectura permite postular que el texto legible está prácticamente completo.

\section{Transcripción}

\section{+ MAR ET ELLA SILET • IN DN II NA DE YO IA C I}

Se aprecia el nexo ET, la abreviatura de $\mathrm{N}$ sobre $\mathrm{E}$ en SILENT mediante pequeño trazo horizontal hacia la izquierda sobre el trazo vertical de la E, las abreviaturas de DOMINO -DN- y la de NONAS -NA- por síncopa, y la de DECEMBRIAS -DE- por abreviación. Las letras finales son de difícil interpretación. La Y podría no ser tal, sino dos trazos independientes, pues de hecho no están ligados. La $\bigcirc$ es clara, así como la abreviatura siguiente, MILLESIMA -MA-, formada por un vástago con trazo superior vuelto, al modo típico de la escritura visigótica. A continuación una $C$, con trazo vertical inferior, a la que sigue un trazo vertical rematado en la parte inferior por una curva hacia la derecha.

\section{Lectura}

$<$ IN DEI NOMINE $>$ MAR $<$ TINVS $>$ ET ELLA SILE $<N>T$. IN $\quad D<O M I>N<O>\quad$ II $\mathrm{N}<\mathrm{ON}>\mathrm{A}(\mathrm{S})$ DE $<$ CEMBRIAS $>$ YO $\mathrm{M}<$ ILLE$S I M>A C<$ ENTESIMA $>$ I

\section{Traducción}

Martín y Ella callan en el Señor. II de las nonas de diciembre, en Yo (Xío), (era) MCl (4 de diciembre del año 1063).

Se trata, por tanto, de la inscripción funeraria o epitafio de un par de individuos llamados ¿Martinus? y Ella, fallecidos el 4 de diciembre del año 1063 en la localidad de Xío, que se encuentra a aproximadamente I $\mathrm{km}$ en línea de aire al NO de Bullaso, en la margen izquierda del Navia. También es razonable suponer que se encuentran enterrados en la citada localidad, aun cuando no hubiera acaecido allí el fallecimiento. Nada presenta de especial el nombre del primero, corriente en las fechas. El del segundo, Ella, excepcional en Asturias, encuentra paralelos en dos documentos de venta bar- celoneses de 916 y 921, referidos a la adquisición de propiedades en el término de Moyá, condados de Manresa y Vic, por el conde Suñer, donde figura este antropónimo entre los confirmantes de ambas piezas (UDINA MARTORELL, 1951: 178, 204). Se trata de un nombre godo: dos personajes que lo portaban suscriben las actas del III (589) y IX (655) concilios toledanos, siendo calificado el primero como vir illustris y el segundo como comes et dux (MARTÍNEZ DÍEZ Y RODRÍGUEZ, 1992: 98, 514).

La fórmula funeraria representa una novedad en Asturias: SILENT IN DOMINO, frente a las más frecuentes que se refieren estrictamente a atestiguar la defunción: OBIIT, OBUIT, OBIT, o a señalar el lugar de la tumba: HIC REQUIESCIT, REQUIEVIT, REQUIEST, HIC IACET, IACENS, SIPULTUS EST (GARCÍA DE CASTRO VALDÉS, 1995: 197). Tampoco se encuentra en el corpus altomedieval vasco (AZKÁRATE Y GARCíA, 1996: 305-306), ni en el elenco de incripciones altomedievales gallegas de Núñez Rodríguez (NÚÑ̃EZ RODRÍGUEZ, 1979). Es extraña la expresión de la fecha, no precedida de la indicación de la Era. No obstante, estimo que la lectura ofrecida se ajusta a las posibilidades de interpretación, y explica la ausencia de texto en el cuarto cuadrante de la corona circular. Tampoco ofrece total seguridad la interpretación de los signos YO como topónimo, identificable con el vecino Xío.

Los rasgos paleográficos merecen comentario. Se trata de letras mayúsculas de módulo alargado, grabadas sin excepción mediante incisión simple, fina, con extremos ensanchados mediante trazos perpendiculares u oblicuos, que en alguos casos forman triángulos incisos, como en la M y A de la primera palabra. La A presenta siempre trazo angular con prolongación hacia abajo. La C -presente sólo como numeral- es redonda, con trazo vertical hacia abajo, a modo de G. La D es redonda. La E, cuadrada, faltándole en trazo horizontal superior. La I carece de remate superior. La L consta de trazo vertical recto, sin prolongación hacia atrás. La M presenta trazo angular con prolongación vertical hacia abajo. La $\mathrm{N}$ es capital, con trazo oblicuo descendente de extremo izquierdo a extremo derecho. La $O$ es ligeramente 
ovalada, de extremos apuntados. La R presenta un ojal estrecho y cerrado. La $S$ es inclinada y de curvas abiertas. La T es de trazo horizontal vuelto hacia atrás, con bucle. La Y -en el caso de que la identificación propuesta se revelara cierta- consta de dos trazos separados. Sólo se observa un signo de interpunción, consistente en un punto situado a media altura del renglón, entre SILENT e IN. Como nexos figuran ET, DN, NA, IA. La inscripción se inicia con una cruz, práctica habitual en la epigrafía funeraria y, en general, constructiva, de la Edad Media. Los tipos de letra más significativos apuntan a inscripciones del XI en la región. Así, la A de trazo angular aparece en Cartavio (1007) y Sangoñéu (I042); la M de similar rasgo, en Cibea ( I083); La R de ojal estrecho y cerrado, en Trevías (1000), Bárcena del Monasterio ( 1 003), Cartavio y Cibuyo ( 1099); y la T esbelta de rasgo horizontal vuelto, en Trevías, Bárcena del Monasterio, Cartavio, así como en Cibea y Cibuyo (IBIDEM: DESP). Por su parte, la I numeral con trazo horizontal vuelto aparece en inscripciones cántabras: La Serna (ca. 1067), Cervatos ( I 129), al igual que la T con trazo horizontal vuelto: La Serna, Santillana del Mar (ca. I08I), Pesquera (1085) y Cervatos (GARCÍA GUINEA, 1979: 580-58I).

La presencia de una estela discoidal funeraria altomedieval constituye igualmente una novedad radical en Asturias, donde hasta el momento no se conocían piezas similares (GARCÍA DE CASTRO VALDÉS, 1995: 536). Es Illamativo el contraste con la vecina Cantabria, donde este tipo funerario es relativamente abundante, como atestiguan las piezas procedentes de las necrópolis de Pie de Concha (Bárcena de Pie de Concha); Izara (Campoo de Enmedio); Retortillo (Campoo de Enmedio) -Museo de Santander n55, 56, 57, 58, 59, 60-; Villaescusa (Campoo de Enmedio) -Museo de Santander n०75-; Espinilla (Campoo de Suso) -Museo de Santander n०76-; Cobejo (Molledo); convento de San Francisco en la capital Santander -Museo de Santander n66, 67, 68-; Saro (Saro) -Museo de Santander n०70-; Las Quintanillas (Valdeolea); Arcea (Valdeprado del Río); Loma Somera (Valderredible); Selaya (Selaya) (BOHIGAS ROLDÁN, 1986: 57; 84; 85-86; 93; 9496; 136-137; 165-166; 169; 179; 181; 230); Salcedo
(Valderredible); Santa Marina (Valdeprado del Río) (LAMALFA Y FERNÁNDEZ, 1992: 512-514); Cérdigo I (Castro Urdiales) (BOHIGAS ET AL, 1992: 520); y Santa María de las Henestrosas (Valdeolea), con pie triangular invertido y cruz latina incisa, fechada a partir del XII (BOHIGAS ET AL, 1992: 22-23, n³). Se trata de estelas discoideas anepígrafas, con representaciones de cruces en su mayor parte griegas, simples o patadas, insertas en ocasiones dentro de círculos delimitados por cicunferencias, en el anverso, de unas dimensiones semejantes a la de Bullaso, para las que se proponen fechas entre los siglos IX y XI. Más al Este, las provincias de Vizcaya y Álava ofrecen estelas discoideas con cruces griegas y latinas, datadas en la Alta Edad Media: Los Castros de Lastra (Caranca, Álava), siglos IX-X; epitafio de Monico Munio (Museo Arqueológico de Álava), siglo Xl; San Julián y Santa Basilisa de Aistra (Zalduendo, Álava), siglos IX$X$; epitafio de Nuninco (San Bikendi de Muntxaraz, Vizcaya), siglo X; epitafio de Enego (Marzana, Vizcaya), siglos X-Xl; epitafio de Belaco (Finaga, Basauri, Vizcaya), siglos IX-X, con la particularidad de disponer la leyenda en el interior de una corona circular, al modo de la de Bullaso; epitafio de Muninco (Andikona, Bérriz, Vizcaya), siglos IX-X; Mendraka (Vizcaya), siglo XI (AZKÁRATE Y GARCÍA, 1996: 131-134; 137-138; 139140; 142-144; 164-1 65; 166; 167- 168; 171-173; 200-201). La pieza asturiana viene a proporcionar un seguro jalón cronológico para este tipo arqueológico, al contar con la fecha inscrita de 1063, y contribuirá a asentar de modo más firme, en función de criterios internos, la seriación cronológica de los tipos de estelas discoidales.

Tipométricamente, la pieza de Bullaso podría insertarse en el grupo A.2 -estelas discoideas pequeñas- definido por estos dos autores, al oscilar sus diámetros y alturas en torno a valores cercanos a los de la pieza asturiana (diámetro inferior a $55 \mathrm{~cm}$ ) (IBIDEM: 270-27I). Los paralelos más claros, entre esta serie, están en las estelas cántabras de Pie de Concha, Izara, Retortillo, Cobejo, San Francisco de Santander, Saro, Las Quintanillas y Selaya, así como en la alavesa de Munico Monio y las vizcaínas de Finaga y Mendraka, emparentadas formalmente con las cántabras citadas. En el corpus vizcaíno se dispone de otra estela con inscripción 
circular, en una pieza de forma tabular: un epitafio anónimo de San Juan de Momoitio, fechado en los siglos IX-X (AZKÁRATE Y CAMINO, 1996: 210-211). Las necrópolis castellanas han proporcionado algún ejemplo de estela discoidea anepígrafa con cruz incisa: Palacios de la Sierra BG (Burgos), fechada en los siglos XIXII (ANDRIO GONZALO, 1992: 53I). El carácter epigráfico de la pieza de Bullaso viene a confirmar la aseveración de Azkárate y García Camino sobre la coexistencia de inscripción y estela funeraria discoidal en el alto Medievo del Norte peninsular (1996: 260-261).

Formalmente, este tipo posee un antecedente en la epigrafía funeraria romana de la región: la inscripción de La Lloraza (Oles, Villaviciosa), cuya leyenda se reparte en renglones horizontales, y cuyo diámetro $(40 \mathrm{~cm})$ se acerca al de la estela de Bullaso, aun cuando la supere en altura $(82 \mathrm{~cm}$ ) (DIEGO SANTOS, 1985: 104-105). En modo alguno, por el contrario, pueden admitirse como antecedentes tipológicos las grandes estelas anepígrafas cántabras o las estelas funerarias romanas de los Valles del Duero y del Ebro con remate o decoración discoidal, que por su volumen y concepción decorativa pertenecen a tradiciones diferentes de la representada por el tipo arqueológico de la pequeña estela medieval.

Aún más Ilamativa es la localización del hallazgo, en pleno valle del Navia, al Occidente de la región. Ello implica la necesidad de explicar el vacío de más de $200 \mathrm{~km}$ lineales existente entre las piezas cántabras y este primer ejemplar asturiano. Al margen de la razón que se proponga, es necesario insistir en la falta de prospección, como ya se apuntaba en 1995 (GARCÍA DE CASTRO VALDÉS, 1995: 521), causa del desigual conocimiento que de estos tipos arqueológicos se posee en los distintos territorios de la Península Ibérica.

Ciñéndonos a la comarca donde se encuentra, el valle medio del Navia, en la vertiente occidental de la Sierra de Carondiu, esta ins- cripción es coetánea grosso modo de la primera mención documental del valle -Ripa de Nauia- (Libro Registro de Corias, $4 \vee A$ ), inserta en la dotación fundacional del monasterio de San Juan Bautista de Corias, en I044 (FLORIANO CUMBREÑO, 1950, II: II; GARCÍA DE CASTRO Y RÍOS, 1997: 87).

\section{Ara del altar de la Capilla de Santa Susana y San Daniel (Casa de la Torre. San Martín del Valledor, Allande) (lám.} 2 y 3; fig. 2).

Ha sido dada a conocer, mediante breve referencia, por García Linares, quien la fecha en el siglo X, calificándola como "del período de la Monarquía Asturiana" (1996: 664). Se encuentra depositada en la capilla de Santa Susana y San Daniel de la Casa de la Torre de San Martín del Valledor (Allande), propiedad del mismo Antonio García Linares, a quien agradezco la cordial acogida y la facilidad para el estudio de la pieza. Procede, según me comunica amablemente el propietario ', de una de las parroquias de presentación episcopal del concejo de Allande. Aun cuando no podamos saber la proveniencia exacta, consta la seguridad del origen allandés.

Se trata de una placa de mármol de contorno trapecial, con unas dimensiones máximas de $32 \times 28^{\prime} 5 \times 3^{\prime} 5 \mathrm{~cm}$. El anverso, completamente pulido, presenta una cruz griega patada incisa, de un solo trazo, con botón central. Penden de los brazos laterales las letras A y $\Omega$, mayúscula la primera, con remates curvos hacia afuera en los trazos oblicuos, y minúscula la segunda, sin ángulo de nexo entre las dos curvas. El brazo inferior apoya sobre otra cruz incisa, a modo de astil. Sobre el brazo superior se encuentra el taladro para la deposición de la reliquia, en la actualidad tapado.

A ambos lados del brazo superior de la cruz han sido grabados los siguientes caracteres epigráficos, verosímilmente con posterioridad al remate de la cruz:

I. En conversación mantenida el 5-5-1998. 
I. Sector izquierdo, parte superior, junto al taladro: $\mathrm{X}$.

2. Sector izquierdo, parte inferior, junto al remate de la cruz: IOANE.

3. Sector derecho, parte superior, junto al taladro: ¿A?, de trazo angular, de cuyo vértice parten dos nuevos trazos en ángulo, divergentes, que se dirigen hacia los rasgos oblicuos de la A. Podría interpretarse como una torpe ejecución del anagrama VERE DIGNVM, con el que se inicia el Prefacio del Canon en la plegaria eucarística del rito romano, conforme a una convención iconográfica que representaba la $\bigvee$ con una cruz interior. De verificarse como cierta esta interpretación, hemos de admitir la posterioridad de este signo, claro indicio de romanización litúrgica, respecto a la labra de los motivos principales de la pieza. Se opone a ella, sin embargo, la posición del signo, casi invertido, a todas luces inadecuado para la expresión de inicio de la plegaria eucarística.

4. Sector derecho, parte inferior, sobre el brazo lateral de la cruz: $\vee$.

Ambos signos $X$ y $V$ pueden ponerse en relación con el antropónimo IOANES. Constituirían así las abreviaturas de $X<$ RISTI $>$ $V<$ ERNVLVS $>$, referido al propio loanes, del modo como el Adefonsus de la placa de Quiloño se calificaba de Christi seruus (MIGUEL VIGIL, |887, II: lám. N || 3).

El reverso de la placa carece de pulido, conservando las huellas de la talla.

Los caracteres paleográficos que figuran en las inscripciones son los siguientes. A abierta, sin trazo angular; con trazo angular. E recta. I con remate de trazos horizontales. $\mathrm{N}$ de trazo derecho curvo y trazo oblicuo descendente de extremo izquierdo a extremo derecho. $\bigcirc$ rómbica. $\vee$ angular.

Estos caracteres permiten una aproximación cronológica. Así, la A abierta, sin trazo horizontal superior figura aparece en 976 (Cartavio, Coaña), 1000 (Trevías, Valdés), I02।
(Fuentes, Villaviciosa) y 1083 (Cibea, Cangas del Narcea); la $\bigcirc$ rómbica aparece en Asturias en el 882 (La Riera, Somiedo), 927 (Bierces/Beroñes, Piloña), 940 (Llamas, Aller), 944 (Serrapio, Aller), 95I (Argüelles, Siero; San Martín de Salas, Salas), 1000 (Trevías, Valdés), 1007 (Cartavio, Coaña), I02I (Fuentes, Villaviciosa), 1042 (Sangoñéu, Tineo), 1083 (Cibea, Cangas del Narcea) y 1099 (Cibuyo, Cangas del Narcea) (GARCÍA DE CASTRO VALDÉS, 1995: DESP.). Este marco cronológico $-2^{\mathrm{a}}$ mitad del $\mathrm{X}$ y $\mathrm{XI}-$ se confirma por los paralelos tipológicos de la pieza. El más directo es el reverso de la inscripción fundacional de San Miguel de Teverga (Teverga), cuyo anverso conserva el texto fechado entre 1036 y 1048 , proporcionando de este modo un terminus ante quem, dado que la inscripción se adaptó al taladro del ara (IBIDEM: 99 100, 631). Esta placa, subrectangular, es formalmente idéntica a la del Valledor, de la que sólo se diferencia por la presencia de la cenefa perimetral con zig-zag. Muy similar es también la placa de Santa María de Leorio (Gijón), fechada en I05। (IBIDEM: |44-|45, 64|), con la particularidad de presentar la decoración y la inscripción esculpidas en resalte y no incisas. Un tercer ejemplo fue recogido por C. Miguel Vigil en 1887, correspondiente al ara de San Miguel de Quiloño (Castrillón) (MIGUEL VIGIL, 1887: 336; GARCÍA DE CASTRO VALDÉS, 1995: 192), que, en función de los caracteres epigráficos de la inscripción depositoria conservada (GARCíA DE CASTRO VALDÉS, 1995: 157-158), podría situarse en torno a fines del IX o principios del $X$.

Similitudes formales, que no tipológico-funcionales, se aprecian en la serie de placas asturianas y gallegas con cruz esculpida: inscripciones procedentes de la Fortaleza ovetense, fechadas en 875 (GARCÍA DE CASTRO VALDÉS, 1995: 88-89, 626; 121-122, 634); placa de la fachada occidental de San Salvador de Valdediós (Villaviciosa) (IBIDEM: 675); inscripción fundacional de San Martín de Salas, fechada en 951 (IBIDEM: 95-96, 630); inscripción deprecatoria del mismo templo (IBIDEM: 136-137, 638); placa de San Martín de Churrio (La Coruña) (LUENGO Y MARTíNEZ, 1969); piezas del Museo Arqueológico de Orense, placa de San Salvador de Samos (NÚÑEZ RODRÍGUEZ, 1978: 230). También, la placa en la fachada occidental de la ermita 
de Santa Cruz de Montes de Valdueza (León), fechada probablemente en 905 (SÁINZ SÁlZ, 1996: 4I-42); y la de Tubilla del Agua (Burgos) (PÉREZ DE URBEL, 1945: 516).

Se desprende de este recorrido una fecha en torno a la segunda mitad del $X$ y primera del XI, 950- 1050 grosso modo, con mayor probabilidad en la primera mitad del Xl.

Cuestión aparte es la del significado del personaje cuyo nombre aparece en la placa: lohannes. La ausencia de mención del cargo -presbiter, monachus, diaconus- podría inclinar la opinión a excluir la pertenencia al clero, si interpretásemos la fórmula hipotética Christi vernulus como simple signo devocional. Ahora bien, no parece posible que el nombre de un laico figurase en una pieza destinada a la consagración. Parece, por tanto, razonable suponer que se trata del clérigo que la mandó hacer o que la labró con sus manos. Reforzaría esta hipótesis la torpeza de la inscripción, sin guardar la horizontalidad en la disposición de las letras, ni la uniformidad en el tamaño, así como el ya referido paralelo de San Miguel de Quiloño.

Las primeras menciones no interpoladas específicas del territorio allandés datan de los años 1085 y 1086 (GARCÍA DE CASTRO Y RÍOS, 1997: 88), refiriéndose al espacio situado al Este de las Sierras de Ourúa, Lagos y El Palo (GARCÍA LARRAGUETA, 1962: 258-260). Las tierras del Valledor, al Oeste de dicha alineación montañosa, no aparecen como tales en la documentación catedralicia ovetense hasta tiempos del obispo Pelayo (I098- I I 30), en sendas composiciones documentales del Liber Testamentorum. La primera está atribuida a Fruela II (9|2):

In territorio Hor monasteria Sancti Martini et Sancti Salvatoris ab omni integritate (GARCíA LARRAGUETA, 1962: 81).

La segunda figura en la donación de Tructino Veremúdiz (972):

In territorio Or nostras portiones in Villam novam et in Tremulato et in Rovoreto et in Cornolio (IBIDEM. I I0).
Ambos documentos son claras falsificaciones (FERNÁNDEZ CONDE, 1971: 169-176; 193-197), sin que se pueda prejuzgar sobre la existencia de donaciones preexistentes que sirvieran de base a la oficina del obispo ovetense. En cualquier caso, en las fechas de compilación del cartulario, a principios del XII, está claramente individualizado el territorio del Valledor, con los núcleos de San Martín, San Salvador, Vilanova, Tremao, Robledo y Cornollo.

No obstante, el Registro Coriense contiene menciones a lugares del Valledor en fechas anteriores: Barras, Fonteta y Vilasonte aparecen vinculados al patrimonio del conde Piniolo Xemeni, fundador del cenobio y fallecido en I 049 (FLORIANO CUMBREÑO, 1950, I: 75; II: 265), que compartía la posesión del tercero con Oveco Roderici. Éste, a su vez, es autor de una donación en Robledo a Corias en 1072, y de su parte en Vilasonte en I077. Por último, Enalso, personaje calificado por el Registro como dompno, donó al monasterio cangués sendas posesiones en Vilanova y Tremao en I089, con lo que se consolidaba la implantación del dominio monástico en el valle.

De los datos anteriores se colige una integración señorial del Valledor en manos del conde Piniolo Xemeni como propietario principal, y de otros miembros de la aristocracia posesora, como Oveco Roderici y Enalso, a principios del XI. A estos propietarios o sus antepasados habría correspondido la erección de los primeros templos, dotados con clero dependiente, entregados al dominio monástico coriense a lo largo del Xl. De ellos, el colocado bajo la advocación de San Martín alcanzaría en tiempos plenomedievales -fines del XII/XIII- la condición parroquial, y como tal figura en el estadismo diocesano elaborado en tiempo del obispo Gutierre de Toledo (I 377 1389). Se da la circunstancia de que San Martín del Valledor está asignado tanto al Arciprestazgo de Grandas - dentro del arcedianato de Ribadeo- como al de Allande-dentro del arcedianato de Tineo. Dentro de este último arciprestazgo, San Martino de Valdeor carece de datos, y es seguido de una mención de San Salvador, sin mayor especificación, mientras que la anotación en el arciprestazgo de Grandas 
contiene los datos habituales sobre derechos de presentación, reparto de diezmos y alcance de la procuración (FERNÁNDEZ CONDE, 1987: 165; 192). Esta doble anotación responde probablemente a la confusión entre límites concejiles y límites arciprestales. Las entidades de población del concejo de Allande se encuentran repartidas eclesiásticamente según la divisoria de aguas Narcea-Navia. La cuenca del Narcea se integra en el arciprestazgo de Allande (La Pola, Besullo, Araniego, Villaverde, Villavaser, Villagrufe, Només, Celón, Beduléu, Linares, Villar de Sapos); la del Navia en el del Grandas (Montefurao, Berducedo, Valledor, Santomillao de Ema, Santa Coloma).

En lo referente al la cuenca del Narcea, la documentación coriense y ovetense es más abundante. Los valles del Meirúa y del Arganza se encuentran dentro del patrimonio familiar del fundador de Corias, Piniolo Xemeni, y de su hermano Sancio Xemeni. Ambos poseen partes en San Juan de Villaverde y su villa, que donan al cenobio coriense, respectivamente, en $1044 \mathrm{y}$, cabe suponer, en torno a mediados de la centuria (FLORIANO CUMBREÑO, 1950, I: 9-13; 71). Es de señalar que la posesión en el valle del Arganza le viene a Piniolo Xemeni por parte de su madre Aragonti -fallecida en 1003, como atestigua su epitafio conservado en el templo paroquial de San Miguel de Bárcena, Tineo- (GARCÍA DE CASTRO VALDÉS, 1995: 64-65), quien, a su vez, dispuso de ella a través de su participación en la propiedad del monasterio de San Miguel de Trevías (Valdés). A este cenobio había sido donado por Nunio Vistelani, capellán de Vermudo II de León (FLORIANO CUMBREÑO, 1950, l: 67).

El valle del Prada está repartido entre los posesores del monasterio de Santa María de Celón, fundado por Tructino Enalso y su esposa Godigeva (IBIDEM: 97) en torno al año 1000 y repartido entre los herederos del matrimonio. La disgregación del patrimonio era patente a fines de la centuria, cuando se atestigua, al menos, el siguiente reparto:

- Rodericus Moniz, famulus Christi, y su madre domna Lexauia donan sus portiones a San Salvador de Oviedo en 1085 (GARCÍA LARRAGUETA, 1962: 258-259).
- Veremudo Guterriz, famulus Dei, donó su portio en el mismo a San Salvador de Oviedo en 1086 (GARCÍA LARRAGUETA, 1962: 259-260).

- En 1092 el abad Munio de Corias permutó su parte en Obona (1/3) por 2/5 del monasterio de Celón con los herederos de Obona. Posteriormente, el mismo abad Munio y sus sucesores continuaron la misma labor de adquisición de partes del monasterio de Celón, hasta completar 2/3 del mismo y convertirse en el maior patronus in eligendo abbate (FLORIANO CUMBREÑO, 1950, I: 96). Esta frase, así como otros testimonios documentales (FERNÁNDEZ CONDE, 1971: 293), atestigua la existencia de auténtica vida cenobítica en Celón, sometida pese a ello a la autoridad coriense.

La implantación de San Salvador de Oviedo se hallaba finalizada a principios del XII, como atestigua el Liber Testamentorum. En el falso testamento de Fruela II (9|2), se explicita el dominio episcopal en el monasterio de San Andrés cum decaneis suis, en el monasterio de San Clemente de Notimas -el actual Només- cum suis decaneis pernominatis infra suos terminos et foris, entre las que se encuentran las ecclesias de Santiago de Linares y San Cipriano de Villavaser (GARCÍA LARRAGUETA, 1962. 82).

En 1214 Alfonso IX de León efectuó un deslinde de los dominios señoriales de San Salvador de Oviedo y San Juan Bautista de Corias y de los bienes realengos en las Asturias occidentales (in totam terram tiniensem), cuyo resultado nos ha sido parcialmente conservado en el Registro de Corias (FLORIANO CUMBREÑO, 1950,I: 174-199, esp. 193-196). La pesquisa confirmó los derechos corienses en el Valledor, separándolos con claridad del realengo.

De esta implantación señorial se derivó el reparto del derecho de presentación de los beneficios parroquiales que figura en el estadismo diocesano del pontificado de Gutierre de Toledo (I 377- | 389). Al obispo de Oviedo correspondían, en la cuenca del Narcea, Santo Andrés de la Puebla de Allande, San Cibrián de Villasel, San Crimente de Només, San Pedro 
de Presnes, Santiago de Villar de Sapos y Santiago de Linares; en la cuenca del Navia, Santa María de Verduzedo, San Martino de Or, Santa María de Pennafonte, Santa María de Tablada. Al abad de Corias, en la cuenca del Narcea, San Martino de Vesullo, San lohán de Araniego, San lohán de Villaverde y San Martino de Beduredo. Santa María de Çelón húsala apresentar el abbad de Çelón (FERNÁNDEZ CONDE, 1987: 165, 190-192).

La cuestión que ahora se plantea es la de insertar el ara de altar -que fechamos por razones tipológicas y paleográficas en torno a la primera mitad del $\mathrm{XI}$ - en este panorama histórico. Concretamente:

I. ¿Corresponde el ara a un templo perteneciente a un dominio particular, siendo así el testimonio de una cristianización -mejor habría que decir eclesialización- dirigida e impuesta por la aristocracia terrateniente?

2. ¿Corresponde por el contrario a un momento anterior a la integración señorial del territorio, y es por tanto testimonio de la cristianización por vía misional, a cargo de la actividad de un presbítero constructor del primer templo?

3. ¿Corresponde a la construcción de un templo una vez entregado el territorio al dominio monástico, actuando el clero como elemento de transmisión de la autoridad señorial?

El hecho de tratarse de un ara de piedra, fechable en la primera mitad del siglo XI, autoriza a proponer un contexto histórico para la misma. Hito de referencia es el canon III, 9 del Concilio de Coyanza (1055), que reza en las dos redacciones conservadas:

\section{A. Omnis altaris ara sit lapidea et ab episcopis consecrata.}

B. Altaris vero ara tota sit lapidea et ab episcopis consecrata. (GARCÍA GALLO, 1950: 293).

Entre los asistentes al sínodo figuraba el obispo Froilán de Oviedo (IBIDEM: 287), a quien correspondió consagrar para el cargo de abad de San Juan de Corias a Ariano o Arias, quien lo ocupó entre 1043 y 1062, sucediendo en el pontificado de Oviedo a Froilán, desde 1073 a 1094, fecha en la que se retiró a Corias, donde murió en 1098 (FLORIANO CUMBREÑO, 1950, II: 49). El Registro coriense incluye un texto detallado del proceso:

Interea clarus in palacio comitis Pinioli ubi Dei Arianus bonis pollebat moribus, a primeva etate studiis litterarum traditus, fidelis et cantus existebat. Hunc videns comes soli Deo militantem confecit eum gradibus ecclesiasticis ordinari et a Froilano Ovetensi episcopo in Monesterio coriensi in ecclesia que nunc est Beatae Mariae in abbatem consecrari abque omni iugo servitutits ecclesie coriensi. (FLORIANO CUMBREÑO, 1950, I: 67).

Al final del mismo códice se incluye incluso la noticia del acta de la consagración abacial de Arias, con la fecha de 1043, en la relación biográfica de este primer abad (IBIDEM: 200).

La relación que de esta circunstancia hubo de derivar entre Froilán y Arias pudo ocasionar que éste se convirtiese en firme valedor de la aplicación de los decretos conciliares en los términos de su jurisdicción. El ara allandesa sería, así, un ejemplo de la puesta en acción de los decretos de Coyanza. Contaríamos, de este modo, con una datación contextual para la pieza perfectamente coherente con la que proporciona el análisis paleográfico y tipológico, por lo que la hipótesis más adecuada entre las tres enumeradas líneas arriba sería la tercera.

Sin embargo, no se puede olvidar que el empleo de la piedra como material exclusivo de la fabricación de altares fue prescrito en el canon XVIIII del concilio de Epaon (5 I7), incluido en la colección hispana (MARTÍNEZ DíEZ Y RODRÍGUEZ, 1984: 196).

\section{Pila bautismal y pila de agua bendita de Santa María de Bullaso (Eilao)}

Inéditas hasta el momento, constituyen dos interesantes elementos arqueológicos de la implantación cristiana altomedieval en el valle medio del Navia. 
3.I. Pila bautismal. Fuera de uso en la actualidad, se encuentra en la capilla situada a la derecha del presbiterio, que hace las veces de sacristía, colocada en vertical apoyada contra la pared de la dependencia. (lám. 4).

Se trata de una pila de contorno oblongo -rectangular con esquinas redondeadaslabrada en un bloque de esquisto, con forma de bañera. Las dimensiones exteriores son $80 \mathrm{~cm}$. de longitud, $56 \mathrm{~cm}$. de anchura y 33 $\mathrm{cm}$. de altura. La cavidad interior mide 62 $\times 43 \times 21 \mathrm{~cm}$. de profundidad. El reborde superior tiene un grosor de $4^{\prime} 5 \mathrm{~cm}$. En los lados menores, este reborde está retranqueado respecto al contorno de la pieza. El desagüe, de $4 \mathrm{~cm}$. de diámetro, se encuentra situado en el centro de unos de los lados, en la arista. El frente está decorado con una serie de II baquetones paralelos verticales, de contorno rectangular, separados por estrías de canto vivo. El fondo de la pila es plano. La disposición del desagüe permite asegurar que la pila careció de soporte, asentándose directamente sobre el pavimento.

3.2. Pila de agua bendita. Se encuentra situada en el tramo posterior del templo, sobre un pie de altar adosado a la pared que sostiene la tribuna de madera. (lám. 5).

Es una pieza de esquisto cilíndrica, de $35 \mathrm{~cm}$. de diámetro y $22 \mathrm{~cm}$. de altura. La cavidad interior, de sección paraboloide, alcanza 27 $\mathrm{cm}$. de diámetro y II de profundidad. Presenta una decoración a lo largo de todo el desarrollo vertical de la pieza, consistente en una serie de baquetones verticales de contorno rectangular, paralelos, separados por acanaladuras de sección triangular, de cantos suavizados, rematados en ambas partes superior e inferior por sendos toros. En la serie de baquetones ha sido retallada una cruz latina con cuadrado central y brazos de remates rectos, delimitada por profundas incisiones agudas, que rompen la serie de baquetones y acanaladuras. Por el diseño de la cruz cabe suponer una fecha tardía para esta modificación, avanzada ya la Edad Moderna.
La unidad de los motivos decorativos mueve a considerar coetáneas ambas piezas. En el territorio asturiano no han sido publicados ejemplares comparables. Tipológicamente, la pila bautismal es anterior a la irrupción de los tipos románicos en forma de copa, que hacen su aparición en Asturias, verosímilmente, a partir de la segunda mitad del XI (GARCíA DE CASTRO VALDÉS, 1995: 245). La presencia del desagüe lateral, las dimensiones y la forma en bañera indican la presencia del rito de inmersión de niños de muy corta edad, recién nacidos, lo que atestigua que estuvo al servicio de una comunidad plenamente cristiana en lo que a los ritos de paso se refiere. Dada la indigencia en la investigación de las pilas bautismales altomedievales hispánicas, el aporte de referencias comparativas ha de resultar forzosamente escaso. En todo caso, pilas de contorno cuadrangular o rectangular se encuentran en San Pedro de Beloncio (Piloña, Asturias), posiblemente altomedieval (IBIDEM: 242); Santa María de Villanueva de Valdecarzana, fechable hacia mediados del XI (IBIDEM: 243-244); San Isidoro de León, coetánea grosso modo de la anterior; Gormaz (Soria) (ORTEGO FRÍAS, 1973: 807-808); San Julián de Bustasur (Las Rozas, Cantabria), cuyo templo se hallaba en remate en 1 I 12 (EÁLO DE SA, 1978: 230; GARCÍA DE GUINEA, 1996: 310-31 I); San Prudencio de Armentia (Álava), fechada en la segunda mitad del XII (BILBAO LÓPEZ, 1994: 24, I I0); Soto de Bureba (Burgos), Santillán del Agua (Burgos), San Miguel de Rosales (Burgos), Santa María de Dosante (Burgos) y San Andrés de Quintanillalabón (Burgos), fechadas genéricamente entre la segunda mitad del XII y primeras décadas del XIII (BILBAO LÓPEZ, 1996: 293, f. 3; 292; 291; 278; 289; 47-48). El tipo pervivió en tiempos bajomedievales, como atestiguan los ejemplares góticos de Santa María de Rípodas y Santa María de Turrillas (Navarra) (DOMEÑO MARTÍNEZ DE MORENTÍN, 1992: 85-87; 60-61).

Baquetones al modo de los de Bullaso, delimitados por sendos boceles, aparecen en la pila navarra de Santa María de Larrión, datada en el XII, donde son interpretados como gallones planos (DOMEÑO MARTíNEZ DE MORENTíN, 1992: 62-63). Otros ejemplares de la misma procedencia - definidos como pilas aristadas, por poseer la copa dividida en dos sectores verti- 
cales por una carena horizontal- incluyen la talla de los gallones de modo semejante al de las piezas asturianas: parroquiales de San Vicente de Ardanaz de Egüés, San Salvador de Eransus y Santa María de Elcano (IBIDEM: 42; 77). Decoración de baquetones paralelos excavados y no en resalte se encuentra en la pila de Susilla (Valderredible, Cantabria), fechada en el XII (EÁLO DE SA, 1978: 233) y en la de Santa María la Mayor de Navamuel (Valderredible, Cantabria), fechada "a muy finales del XII o principios del XIII" (GARCÍA GUINEA, 1996: 322323). La ausencia de baquetones en los otros tres lados de la pieza pone en guardia frente a la interpretación como gallones de una venera, tema abundante en la iconografía de las pilas bautismales románicas.

Ambas piezas asturianas poseen, pese a todo, motivos decorativos de larga vigencia medieval. La aproximación a la cronología no puede, por ello, basarse en los mismos. Tipológicamente, la forma en bañera parece desconocida en el inventario románico -desde mediados del $\mathrm{XI}$ a primeras décadas del XIII-, mientras que encuentra analogías con pilas bajas, sin soporte, características de tiempos altomedievales, cuando no se ha alcanzado la canonización de los tipos y pervive la tradición de las instalaciones bautismales de la Antigüedad Tardía. Por ello, y a título estrictamente provisional, proponemos para estas piezas una fecha entre el siglo $X$ y la primera mitad del XI. Refuerza esta opinión la difusión en la relativamente cercana cuenca alta del Narcea de un tipo de pila bautismal sobre soporte cilíndrico y copa hemiesférica baja, decorada con arquillos ciegos y acanaladuras radiales - Santiago de Cibea, Santa María de Agüera de Castanéu, San Salvador de Cibuyo-, que pertenecen a monasterios documentados en la primera mitad del XI y que cuentan con apoyo epigráfico para la datación ( 1083 para Cibea, I 66 para Agüera de Castanéu) (GARCíA DE CASTRO VALDÉS, 1995: 245, nota 375). Si las pilas aludidas pueden derivar de los momentos fundacionales referidos por las inscripciones, las piezas de Bullaso podrían corresponder a tiempos anteriores, tal y como proponemos.

\section{Tenante de altar de Santa María de Bullaso (Eilao)}

Se encuentra depositado junto a la pila bautismal. Consiste en un prisma cuadrangular de esquisto, con esquinas achaflanadas, lo que produce una sección octogonal irregular. La altura es de $57 \mathrm{~cm}$. y la sección de $26 \times 27 \mathrm{~cm}$. En la superficie superior dispone de loculus para las reliquias, cuadrangular, con una sección de $9 \times 10 \mathrm{~cm}$. y una profundidad de $15 \mathrm{~cm}$. Carece de decoración y la labra es muy tosca, dificultada por la calidad de la piedra.

Es pieza de tipología muy genérica, con ascendencia altomedieval hasta tiempos avanzados del Medievo. En Asturias contamos con el paralelo de San Salvador de Deva (Gijón), fechable a fines del X (GARCÍA DE CASTRO VALDÉS, 1995: 207). La presencia de las pilas estudiadas en el apartado precedente, con una cronología semejante, mueve a asignar al mismo horizonte esta pieza, que verosímilmente formó parte del primer altar erigido en el templo, constituyendo el soporte central único de una mesa de reducido tamaño.

\section{Ventana exenta de Santo Tomás de Priandi (Nava) (lám. 6).}

La primera noticia al respecto, acompañada de fotografía, se debe a Martínez Faedo y Díaz García (1995: 233-234). Posteriormente, la recogen, con fotografía, García de Castro Valdés y Ríos González (1996: 45-46). Por último, ha sido objeto de estudio por Manzanares Rodríguez (1996: 53-54). Los primeros la describen como "pequeña ventana geminada de cronología altomedieval". Los segundos la integran en el tipo de "ventanas concebidas como piezas aisladas del paramento", definido en 1995 por García de Castro Valdés (1995: 247-252). Por su parte, Manzanares la inserta en la "serie asturiano-mozárabe", señalando "un regusto de mozarabismo" y asignándole fecha en "un momento entre los siglos $X$ y Xl" 2 .

2. Es notorio que la publicación de Manzanares no cite las referencias de los que le precedieron en la tarea. De igual modo, tampoco menciona la lectura y transcripción de los epígrafes de Santiago de Sariego que publiqué en 1995 (pp. 250-25I), al referirse a ellos dentro del mismo trabajo. 
Está empotrada en el exterior del muro meridional de la capilla de Santo Tomás de Priandi (Nava), bajo el alero de la cubierta. Está labrada en una lastra rectangular de $65 \times$ $47 \times 12 \mathrm{~cm}$. Bífora, consta de dos huecos verticales alargados, rectangulares rematados en arco de herradura-de $9 \mathrm{~cm}$. de diámetro, según Manzanares-, prolongado aproximadamente los 4/5 del radio. El parteluz tiene sección rectangular. Junto con las jambas posee impostas voladas de perfil triangular. Sobre los vanos han sido taladrados otros dos huecos de contorno semicircular peraltado, de base horizontal. No figuran otros rasgos decorativos, como capiteles, collarinos, basas, molduración del trasdós o la rosca, motivos en las enjutas o en el fuste del parteluz...

Los paralelos más cercanos dentro del grupo asturiano son los ejemplares de San Lorenzo de Cortina (Llaranes, Avilés), San Cipriano de Pillarno (Castrillón) (GARCÍA DE CASTRO VALDÉS, 1995: 247-248) y San Bartolomé de Puelles (Villaviciosa) (GARCÍA DE CASTRO VALDÉS, 1996: 281 284), caracterizados por poseer un pilarcillo como parteluz y dos huecos cerrados -Cortina- o de pronunciada prolongación del arco -Pillarno y Puelles-. No obstante, la diferencia de la pieza de Nava estriba en la proporción alargada, la talla en pieza rectangular y la presencia de los dos huecos superiores. En Asturias, dentro de una muy superior calidad formal, se encuentran vanos bíforos rematados en arco de herradura y con tres huecos superiores en las tres ventanas de Santiago de Sariego (Sariego), talladas en piezas perfectamente rectangulares (GARCÍA DE CASTRO VALDÉS, 1995: 250-25I). Tipos de ventana con dos series de huecos circulares o subcirculares aislados de los vanos principales son relativamente abundantes en Vizcaya. A modo de ilustración, destacan las piezas bíforas dotadas de dos huecos circulares: San Pedro de Arta (Markina-Xemein), San Miguel de Urrieldu (Gorozika-Muxika), San Lorenzo de Bermejillo (Güeñes), San Martín de Amatza (lurreta-Durango), entre las que carecen de elementos decorativos, si exceptuamos la columnilla-parteluz (GARCÍA CAMINO ET AL, 1987: 31; 32; 37). La peculiaridad del caso naveto estriba en que posee vanos rematados en arco y huecos cerrados, circunstancia en la que no se encuentra ninguno de los ejemplos vizcaínos citados, ni otros similares, dotados de mayor riqueza decorativa: San Lorenzo de Isla (Gautegiz de Arteaga) o San Salvador de Zarandoa (Larrabetzu) (IBIDEM: 35; 37). En la Galicia meridional se han conservado ejemplos similares a los vizcaínos, con una mayor calidad formal: San Lorenzo de Melias (Orense) o Santa Eufemia de Ambía (Orense) (RIVAS FERNÁNDEZ, 197I; 1974).

Cronológicamente, por ello, parece segura la adscripción al siglo $X$, probablemente en sus décadas centrales, constituyendo una verosímil irradiación del cercano ejemplo de Santiago de Sariego. Dado que en este templo la presencia de tres ventanas parece atestiguar la existencia de una fábrica preexistente dotada de triple cabecera rectangular, semejante en su aspecto al testero de Santa Eufemia de Ambía (Orense), fábrica al servicio de una verosímil comunidad monástica atestiguada en los años centrales del siglo X (GARCÍA DE CASTRO VALDÉS, 1995: 25 I), no parece descabellado suponer una relación de dependencia entre el cenobio de Sariego y este templo de Nava, separados por escasos 5'5 km en línea de aire.

Otro problema reside en la definición "cultural", explícita en la propuesta de Manzanares, al aludir al "regusto mozárabe" o a la "serie astur-mozárabe" en la que se integra esta pieza. A este respecto, me limito a reiterar lo expuesto a propósito de la ventana de Puelles (1996: 283). Estas ventanas pueden considerarse traducciones populares de los vanos más elaborados característicos de la arquitectura altomedieval de los siglos IX y X. Han de considerarse, por tanto, coetáneos a ellos, aun cuando tipológicamente constituyan una copia de la arquitectura de escuela, ejemplificada, dentro de la comarca, por San Salvador de Valdediós (consagrada en 893). Ni la forma en herradura de los calados, ni la decoración -inexistente en este caso- constituyen elementos sólidos para afirmar la habitual clasificación de estas piezas como "ventanitas mozárabes", en el supuesto improbable de que tal denominación -el mozarabismo- responda a una enti- 
dad culturalmente definible y arqueológicamente identificable ${ }^{3}$.

No poseemos menciones documentales coetáneas del lugar de Priandi. La primera aparición está datada en 1227, año en el que Diego Ordonniz, prior de Santo Tomás, suscribe como testigo un documento de permuta del monasterio de San Bartolomé de Nava. El mismo personaje continuaba en el cargo en 1252 (TORRENTE FERNÁNDEZ, 1982: 210-211). Este priorato disfrutaba del derecho de presentación del párroco a fines del XIV, según el estadismo diocesano del obispo Gutierre de Toledo (FERNÁNDEZ CONDE, 1987: 140).

\section{BIBLIOGRAFÍA}

ANDRIO GONZALO, J. (1992): "Estelas de la necrópolis medieval de Palacios de la Sierra (Burgos)". III Congreso de Arqueología Medieval Española, II. Comunicaciones, Oviedo, pp. 526-533.

AZKÁRATE GARAI-OLAUN, A. y GARCÍA CAMINO, I. (1996): Estelas e inscripciones medievales del País Vasco (siglos VI-XI). I. País Vasco occidental. Bilbao, Universidad del País Vasco/Gobierno Vasco.

BILBAO LÓPEZ, G. (1994): Simbolismo e iconografía bautismal en el arte medieval alavés. Vitoria, Diputación Foral de Álava.

BILBAO LÓPEZ, G. (1996): Iconografía de las pilas bautismales del románico castellano. Burgos y Palencia. Burgos, La Olmeda.

BOHIGAS ROLDÁN, R. (1986): Yacimientos arqueológicos medievales del sector central de la montaña cantábrica. Santander, Asociación Cántabra para la defensa del patrimonio subterráneo.

BOHIGAS ROLDÁN, R., MOLINERO ARROYABE, J. T., SARABIA ROGINA, P. M., GARCÍA ALONSO, M. (1992): "Aportación al Corpus de las estelas discoidales de Cantabria (Edad Media y Moderna)". III Congreso de Arqueología Medieval Española, II. Comunicaciones, Oviedo, pp. 519-525.

BOHIGAS ROLDÁN, R., GARCÍA ALONSO, M., SARABIA ROGINA, P. (1992): "Necrópolis de Santa María de Las Henestrosa (Valdeolea, Cantabria) (campaña 1986)". Trabajos de Arqueología en Cantabria. Santander, Asociación Cántabra para la defensa del patrimonio subteráneo, pp. 13-32.
DIEGO SANTOS, F. (1985): Epigrafía romana de Asturias. Oviedo, Instituto de Estudios Asturianos.

DOMEÑO MARTíNEZ DE MORENTÍN, A. (1992): Pilas bautismales medievales en Navarra: tipos, formas y símbolos. Pamplona, Gobierno de Navarra.

EÁLO DE SA, M. (1978): El románico de Santander en sus cinco colegiatas. Santander, Institución Cultural de Cantabria.

FERNÁNDEZ CONDE, F. J. (197I): El Libro de los testamentos de la catedral de Oviedo. Roma. Iglesia Nacional Española.

FERNÁNDEZ CONDE, F. J.( (987): La Iglesia de Asturias en la Baja Edad Media. Estructuras económico-administrativas. Oviedo, Instituto de Estudios Asturianos.

FLORIANO CUMBREÑO, A. C. (1950): El Libro Registro de Corias. 2 Vols. Oviedo, Instituto de Estudios Asturianos.

GARCÍA CAMINO, I., GONZÁLEZ CEMBELLÍN, J.M., SANTANA EZQUERRA, A. (1987): "La arquitectura prerrománica vizcaína". Kobie-Bellas Artes,4, pp. 7-37.

GARCÍA GALLO, A.(1950): "El concilio de Coyanza. Contribución al estudio del derecho canónico en la Alta Edad Media". Anuario de Historia del Derecho Español, XX, pp. 275-633.

GARCÍA GUINEA, M. A. (1979): El Románico en Santander. 2 vols. Santander, Librería Estudio.

GARCÍA GUINEA, M. A.(1996): Románico en Cantabria. Santander, Librería Estudio.

GARCÍA LARRAGUETA, S. (1962): Colección de documentos de la catedral de Oviedo. Oviedo, Instituto de Estudios Asturianos.

GARCÍA LINARES, A. (1996): "La capilla de los Santos Daniel y Susana en la Casa del Valledor (Allande)". BRIDEA, 146.

GARCÍA DE CASTRO VALDÉS, C. (1995): Arqueología cristiana de la Alta Edad Media en Asturias. Oviedo, Real Instituto de Estudios Asturianos.

GARCÍA DE CASTRO VALDÉS, C.(1996): "La ventana altomedieval de San Bartolomé de Puelles (Villaviciosa)". BRIDEA, I47, pp. 28I-284.

GARCÍA DE CASTRO VALDÉS, C. y RÍOS GONZÁLEZ, S. (1996): Introducción a la arquitectura en Asturias en los siglos VIII-X. Pola de Lena, Ayuntamiento de Lena.

GARCÍA DE CASTRO VALDÉS, C. y RÍOS GONZÁLEZ, S. (1997): Asturias medieval. Gijón, Ediciones Trea.

3. Es de lamentar la pervivencia de conceptualizaciones manifiestamente ideologizadas y trasnochadas -como el concepto de mozárabe, o el de reconquista, o el de despoblación y repoblación- en el estudio de las manifestaciones históricas altomedievales. El prestigio de quienes las elaboraron, cuya calidad intelectual está fuera de duda (Gómez Moreno, Sánchez Albornoz), pesa como un lastre en la erudición local, por no referirnos a los epígonos asentados en la academia. 
LAMALFA DÍAZ, A. C. y FERNÁNDEZ IBÁÑ̃EZ, C. (1992): "Aportación al mundo de las estelas medievales de las montañas cántabras". III Congreso de Arqueología Medieval Española, II. Comunicaciones, Oviedo, pp. 5I2-5I7.

LÓPEZ ROCA, A. (1997): "Illano". Asturias a través de sus concejos. Oviedo, Prensa Asturiana, pp. I49-I54.

LUENGO Y MARTÍNEZ, J. M. (1969): "La Santa Cruz de Aranga". Cuademos de Estudios Gallegos, XXIV, 72-74, pp. $4 \mid-48$.

MANZANARES RODRÍGUEZ, J. (1996): "Santitomé de Priandi (Nava) y su ventanina mozárabe". Crónica monumental asturiana. Tabularium I. Oviedo, Tabularium Artis Asturiensis, pp. 49-60.

MARTIINEZ DÍEZ, G. y RODRÍGUEZ, F. (1984): La colección canónica hispana, IV: concilios galos e hispanos $1{ }^{a}$ parte. Madrid, CSIC-Instituto Enrique Flórez.

MARTÍNEZ DÍEZ, G. y RODRÍGUEZ, F. (1992): La colección canónica hispana, V: concilios hispanos $2^{a}$ parte. Madrid, CSIC-Instituto Enrique Flórez.

MARTÍNEZ FAEDO, L. y DÍAZ GARCÍA, F. (1995): "Carta arqueológica de Nava". Excavaciones Arqueológicas en Asturias 3 (1991-1994). Oviedo, Principado de Asturias, pp. 232-235.

MIGUEL VIGIL, C. (I 887): Asturias monumental, epigráfica y diplomática. 2 vols. Oviedo, Diputación Provincial.

NÚÑEZ ROGRÍGUEZ, M.(1978): Arquitectura prerromanica. Historia da arquitectura galega. Santiago de Compostela, COAG.

\section{RESUMEN}

Se publican seis nuevas piezas arqueológicas altomedievales procedentes de Asturias (España): una estela discoidea funeraria fechada en 1063, un ara de altar fechada entre los siglos X-XI, una pila bautismal y otra pequeña pila de tipología altomedieval, un tenente de altar y una ventana bífora, fechada en el siglo X. La estela presenta la particularidad de ser la primera que aparece en territorio asturiano. Las investigaciones futuras podrán contar con la valiosa referencia cronológica de su inscripción.

\section{PALABRAS CLAVE:}

Asturias. Arqueología medieval. Epigrafía.
NÚÑEZ RODRÍGUEZ, M. (1979): "Inscripciones de la Galicia altomedieval". Revista de Guimarâes, LXXXIX, pp. 293-320

ORTEGO FRÍAS, T.(1973): "Miscelánea arqueológica soriana". XII Congreso Nacional de Arqueología. Zaragoza, pp. 805-808.

PÉREZ DE URBEL, J. OSB (1945): Historia del condado de Castilla. 3 vols. Madrid, CSIC-Escuela de Estudios Medievales.

RIVAS FERNÁNDEZ, J. C. (197I): "Algunas consideraciones sobre el prerrománico gallego y sus arcos de herradura geminados". Boletín Auriense, I, pp. 61-125.

RIVAS FERNÁNDEZ, J. C. (1974): "Una ventana geminada prerrománica en Arcos de Valdeorras". Boletín Auriense, 4, pp. 250-254.

SÁINZ SÁIZ, J. (1996): Arte prerrománico en Castilla y León. León, Ediciones Lancia.

TORRENTE FERNÁNDEZ, I. ( 1982): El dominio del monasterio de San Bartolomé de Nava (siglos XIII-XVI). Oviedo, Universidad de Oviedo.

UDINA MARTORELL, F. (|95I): El archivo condal de Barcelona en los siglos IX-X. Estudio crítico de sus fondos. Barcelona, CSIC-Escuela de Estudios Medievales.

V.AA. (1996): "Illano". Gran Atlas del Principado de Asturias. Vol. III: Oscos, Eo, Navia. Oviedo, Ediciones Nobel.

\section{RÉSUMÉ}

On publie six nouvelles pièces archéologiques de l'Haut Moyen Âge provenant des Asturies (Espagne): une stèle funéraire datée en 1063, une ara altaris datée aux XXlème siécles, une cuve baptismale et une autre petite cuvette, toutes les deux appartenant à l'Haut Moyen Âge d'aprés leur typologie, un support d'autel et une fenêtre à double vain, datée au Xème siécle. II s'agit de la première stéle funéraire discoïdale que l'on trouve aux Asturies. L'on tiendra bien compte dans le futur de la valeur chronologique de l'inscription qu'elle porte.

\section{MOTS CLÉ:}

Asturies. Archéologie médiévale. Epigraphie. 


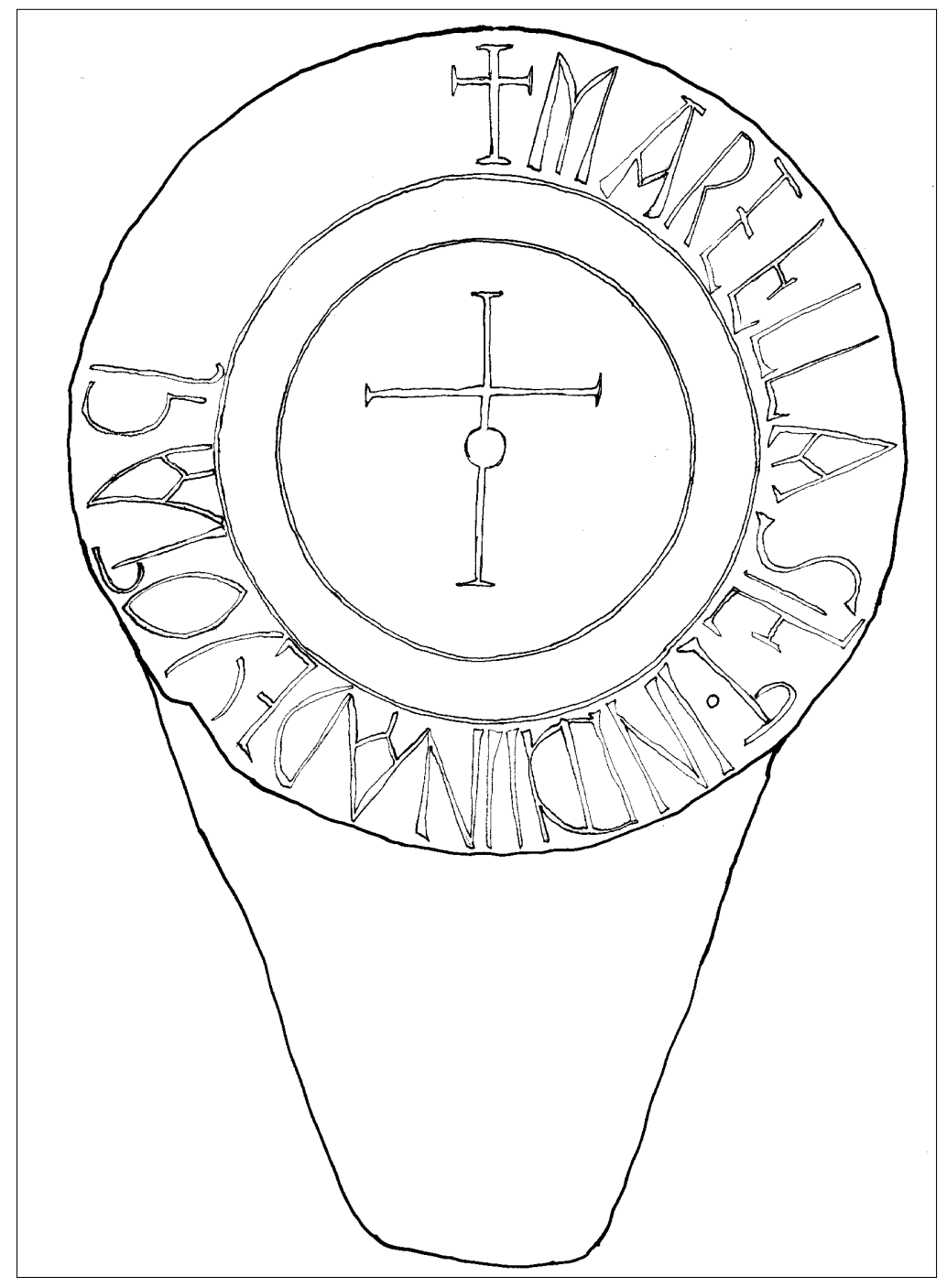

Fig. I. Estela discoidea

de Santa María de Bullaso.

Fig. 2. Ara de altar de San Martín del Valledor.

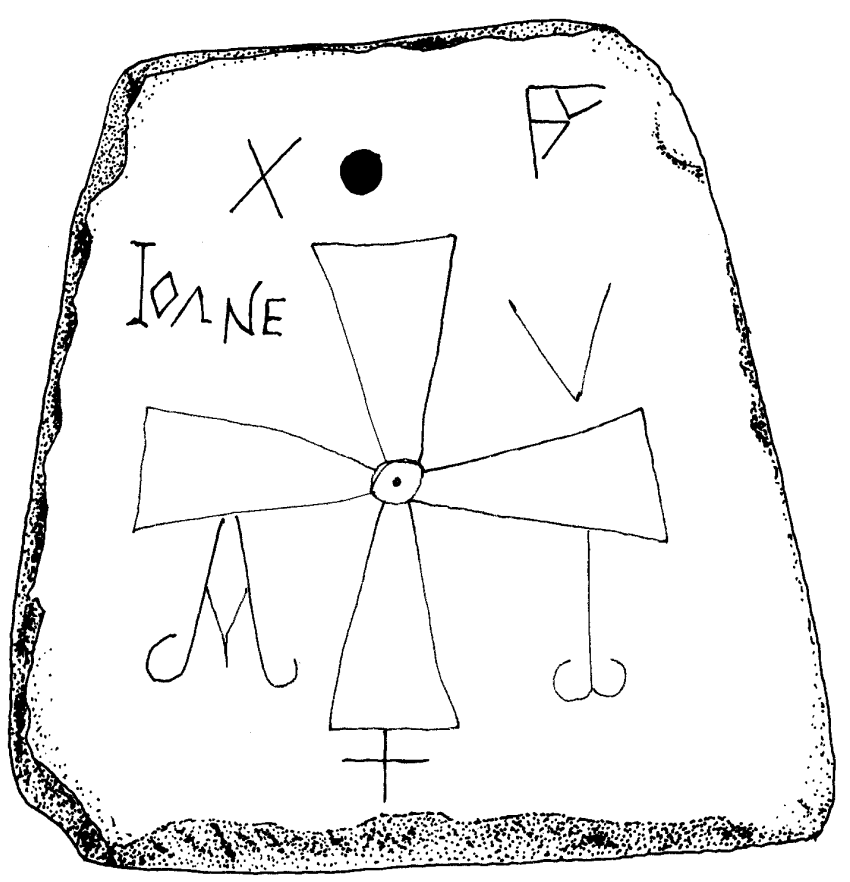




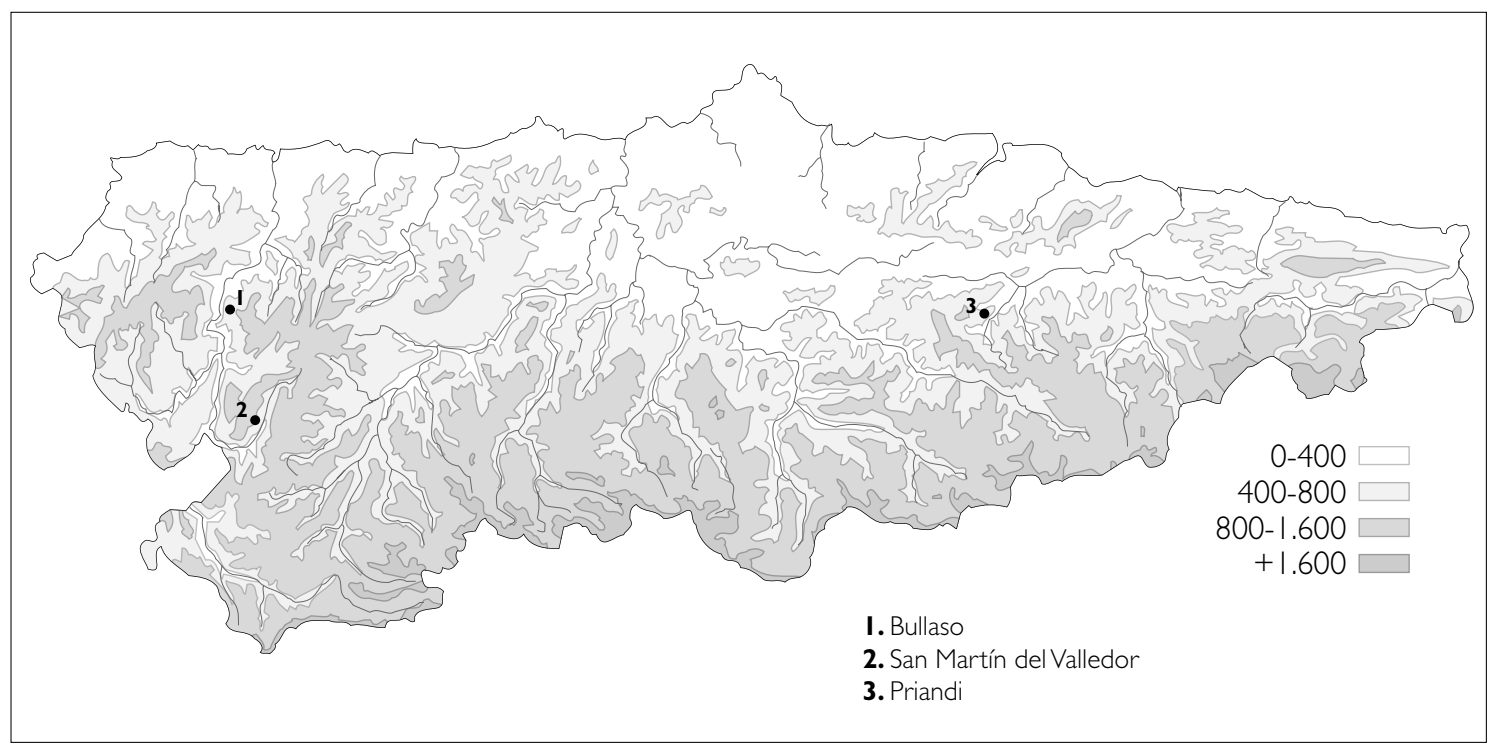

Fig. 3. Mapa de Asturias con la situación de las piezas estudiadas en el texto.

Lám. I. Estela discoidea

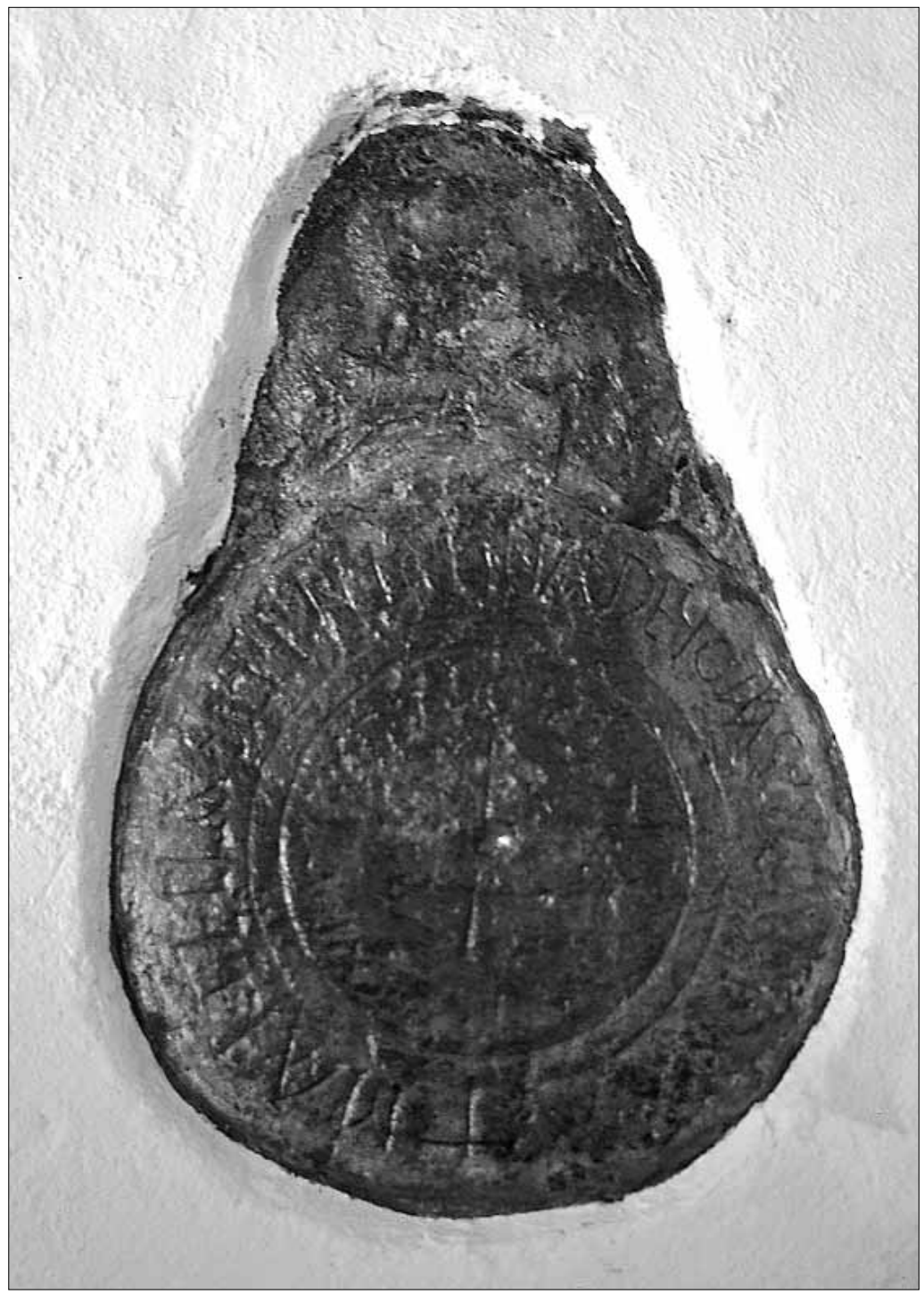
de Santa María de Bullaso. 


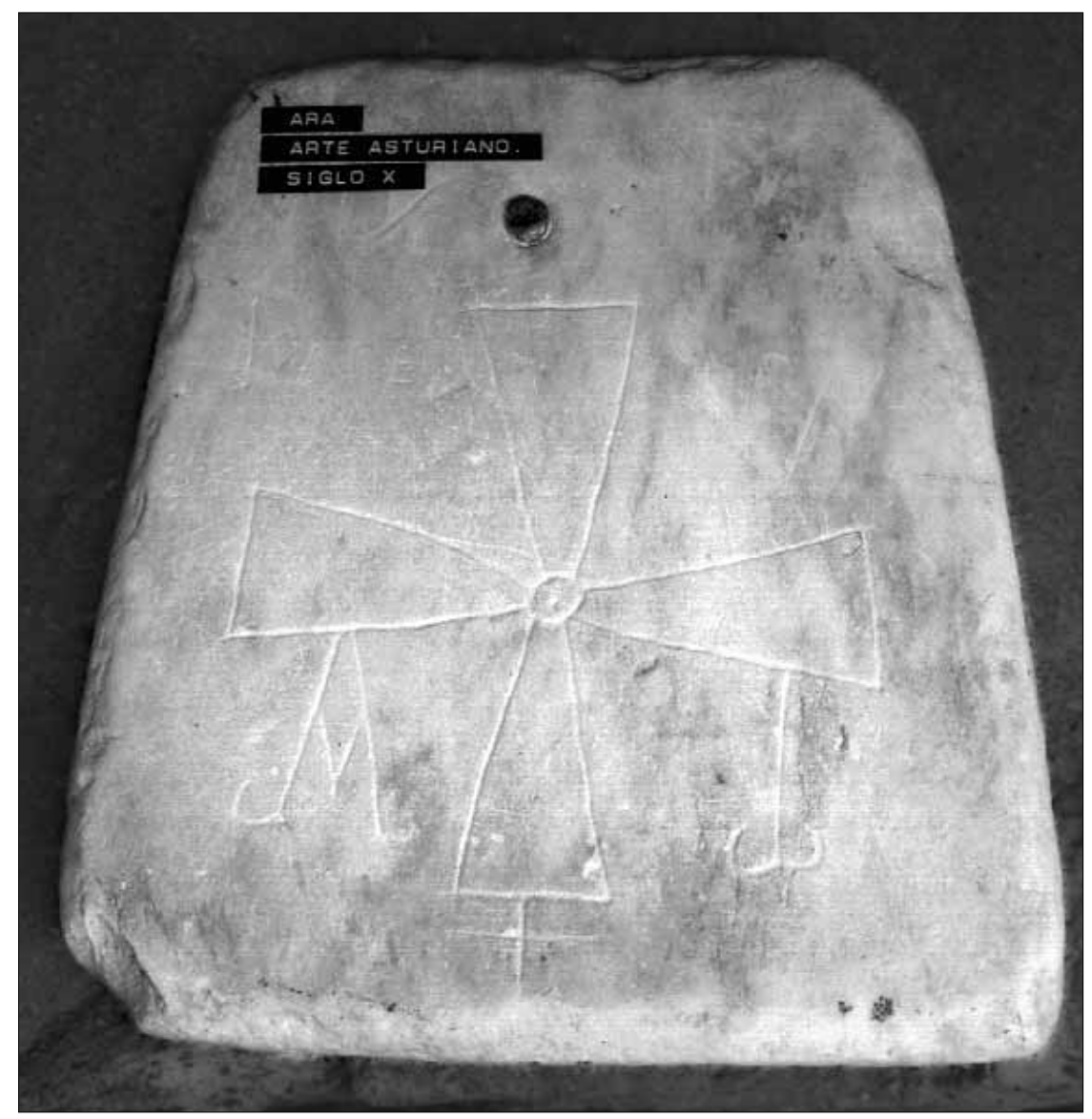

Lám. 2. Ara de altar de San Martín del Valledor. Anverso.

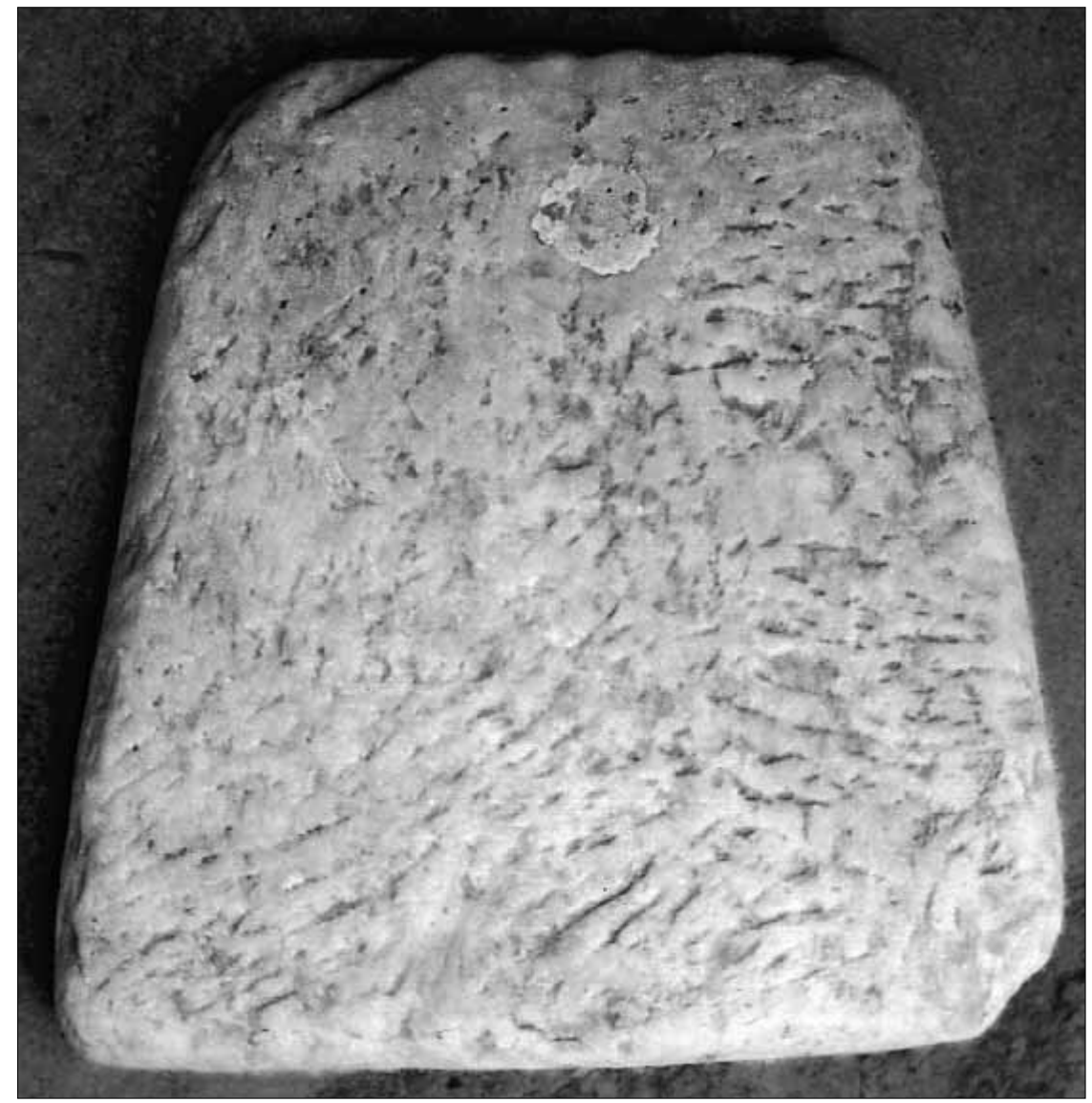

Lám. 3. Ara de altar de San Martín del Valledor. Reverso. 


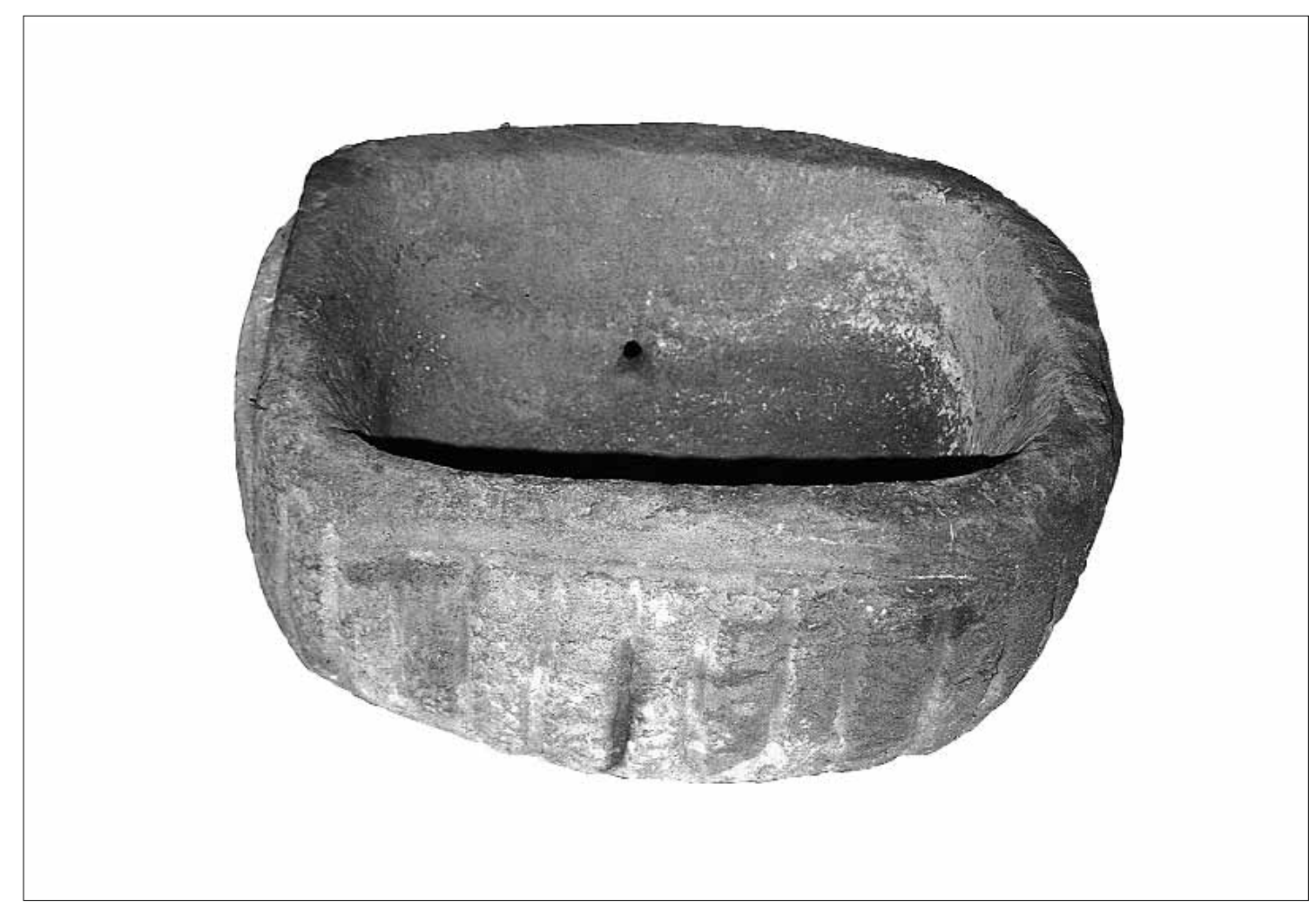

Lám. 4. Pila Bautismal de Santa María de Bullaso.

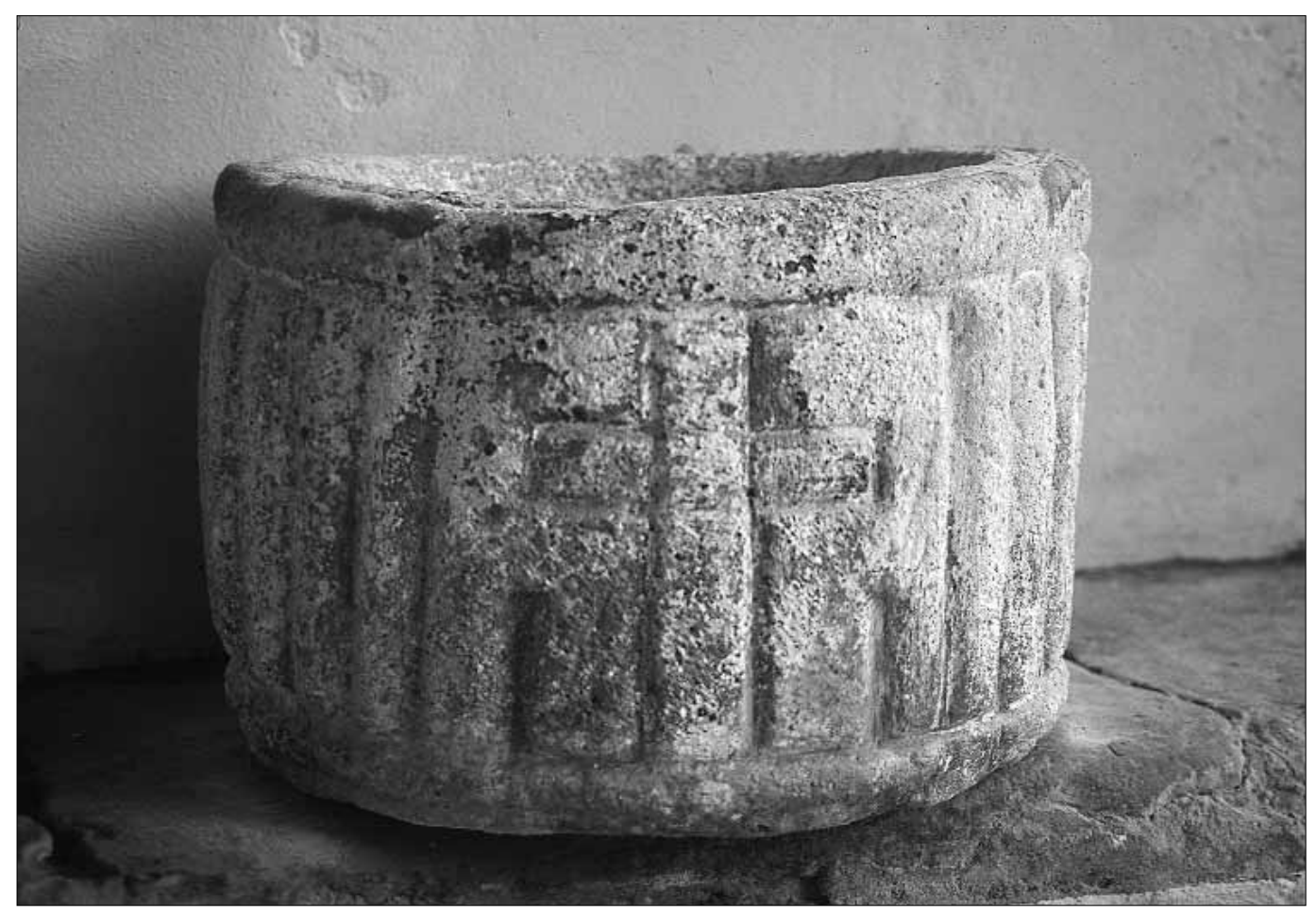

Lám. 5. Pila de agua bendita de Santa María de Bullaso. 


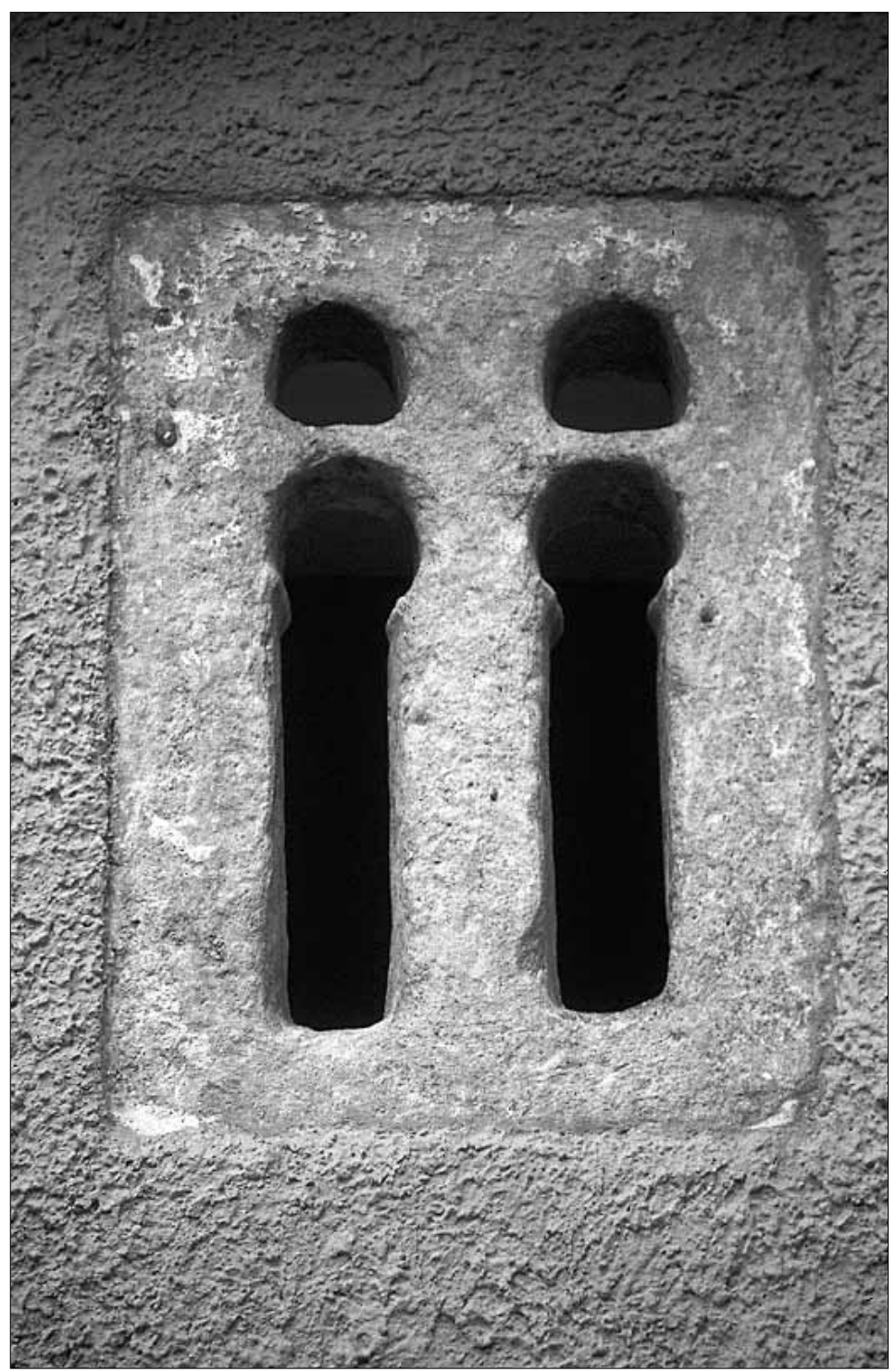

Lám. 6. Ventana bífora de Santo Tomás de Priandi. 